\title{
International Crimes in the Digital Age: Challenges and Opportunities Shaped by Social Media
}

\author{
Chiraz Belhadj Ali* \\ DOI: $10.21827 /$ GroJIL.9.1.43-59
}

Keywords: SOCIAL MEDIA, USER-GENERATED EVIDENCE, INDIVIDUAL CRIMINAL RESPONSIBILITY

\begin{abstract}
Due to the growing influence of social media on the dynamics of international criminal law, the investigation and prosecution of international crimes have taken an entirely new dimension. Particularly, the increasing use of these platforms has led to the rise of new types of evidence, namely user-generated evidence thus creating considerable opportunities, but also unique legal challenges. Indeed, while social media became a source of evidence for public authorities, these same platforms are used to fuel offline brutality and atrocities. This article thus provides a comprehensive insight into the advantages and disadvantages produced by the growth of usergenerated evidence. It also calls for a necessary legal change to accommodate the digital age. Indeed, it is imperative to adjust the existing legal framework in order to contain the downsides of user-generated evidence on the one hand, and promote their effective use in the International Criminal Court to promote justice and transform UGE in the much needed mine of evidence.
\end{abstract}

\section{Introduction}

The cyber age we are witnessing has prompted the digitalization process at an exponential pace and has largely contributed to the astonishing popularization of social media. ${ }^{1}$ It is no exaggeration to assert that the latter forms an integral part of individuals daily activities and thus produces an unprecedented global interconnectedness. ${ }^{2}$ The rise of these social networks and their ever growing popularity has tremendously altered not only the individuals' private sphere but also the public domain. Indeed, social media is substantially affecting the world's dynamics and proves to be particularly true when it comes to the legal realm. ${ }^{3}$ As a matter of fact, in this digital era, these massive online platforms give rise to new challenges and opportunities in relation to the existing framework of international criminal law (hereinafter 'ICL'). Hence, due to the new aspects it must incorporate in the investigative processes, the prosecution of international crimes is gaining greater complexity. ${ }^{4}$ In this context, it is noteworthy that this development produces both advantageous consequences and significant harm simultaneously. Indeed, on the one hand, an important aspect of social media is the fact

\footnotetext{
Trainee at the Council of the EU; LL.M graduate with Honours in European Criminal Justice in a Global Context at Utrecht University. Graduated cum laude with Honours from LL.B in International and European Law at the University of Groningen.

1 Mylona Ifigeneia and Amanatidis Dimitrios, 'Globalization, Social Media and Public Relations: A Necessary Relationship for the Future?' in Persefoni Polychronidou and Anastasios Karasavvoglou (eds) The Economies of the Balkan and the Eastern European Countries in the changing World (KnE Social Sciences 2018) 309-320.

2 ibid.

3 Jeremy Harris Lipschultz, Social Media Communication: Concepts, Practices, Data, Law and Ethics (2nd edn, Routledge 2018) 233-260.

4 Isabella Bank, 'International Criminal Liability in the Age of Social Media: Facebook's Role in Myanmar (PILPG, 13 February 2019) <www.publicinternationallawandpolicygroup.org/lawyering-justiceblog/2019/2/13/international-criminal-liability-in-the-age-of-social-media-facebooks-role-in-myanmar> accessed 1 July 2021.
} 
that it constitutes a worldwide accessible platform for the documentation of human rights violations and atrocities perpetrated. ${ }^{5}$ Indeed, online wars and brutality that materialize find their roots in social media which implies that the latter represents an open source for evidence. Thus, the digital ecosystem is transformed into a precious information database for the investigative process. The proliferation and growing use of such evidence delineates how social media is revamping the paradigm of ICL. ${ }^{6}$ Nonetheless, the reliance on user-generated evidence (hereinafter 'UGE') derived from online platforms remains all the more controversial mainly due to issues of credibility, fairness and reliability. Such issues urge the development of a binding framework to govern UGE and eventually fill in the legal lacuna. On the other hand, it is evident that social media, such as Facebook and Twitter, have been instrumentally used by legal or natural persons for hate propaganda and disinformation. ${ }^{7}$ Many governments' campaigns, for instance, revolve around sharing inflammatory posts, fake news and hatred. ${ }^{8}$ Accordingly, they establish a climate of hate and animosity and constantly nourish it to pursue their political objectives to the detriment of international peace and security. This phenomenon has been coined as 'the weaponization of social media', which results in the practice of widespread brainwashing and indoctrination of States' populations. ${ }^{9}$ Accordingly, these channels of communication and information exchange set the ground for the commission of international crimes and play a significant role in fuelling atrocities. ${ }^{10}$ This phenomenon drew the attention of the international community and raised the issue of what it could entail in terms of individual criminal responsibility (hereinafter 'ICR') under ICL. ${ }^{11}$

Accordingly, this article seeks to study the rise of this new type of evidence and highlight its implications for the legal realm. It will answer the following question: what are the positive and negative impacts of social media on the realm of ICL, and in particular, the investigation and prosecution of international crimes?

\section{Setting the Context: The ICC, Evidence Gathering and Social Media}

The ICC is an intergovernmental organization and the first permanent international court, established by the Rome Statute of the International Criminal Court (hereinafter 'RS') upon its ratification by 60 States in 2002. ${ }^{12}$ The ICC today counts 123 State Parties (hereinafter 'SP') and sits in The Hague, in the Netherlands. ${ }^{13}$ Its mandate consists of investigating and prosecuting

5 Human Rights Watch, 'Social Media's Moral Reckoning' (Human Rights Watch, 21 December 2018) <www.hrw.org/news/2018/12/21/social-medias-moral-reckoning> accessed 1 July 2021.

6 Rosine Faucher, 'Social Media and Change in International Humanitarian Law Dynamics' (2019) 2(1) Inter Gentes 48, 51.

7 Zachary Laub, 'Hate Speech on Social Media: Global Comparison' (Council on Foreign Relations, 7 June 2019) <www.cfr.org/backgrounder/hate-speech-social-media-global-comparisons> accessed 1 July 2020.

8 ibid.

9 For example, see Alexander Tsesis, 'Social Media Accountability for Terrorist Propaganda (2017) 86(2) Fordham Law Review 605, 605-613.

10 Zachary Laub (n 7).

11 Talita de Suza Dias, 'Propaganda and Accountability for International Crimes in the Age of Social Media: Revisiting Accomplice Liability in International Criminal Law (OpinioJuris, 4 April 2018) $<$ http://opiniojuris.org/2018/04/04/propaganda-and-accountability-for-international-crimes-in-the-age-ofsocial-media-revisiting-accomplice-liability-in-international-criminal-law/> accessed 1 July 2021.

12 Rome Statute of the International Criminal Court (adopted 17 July 1998, entered into force 1 July 2002) 2187 UNTS 90 (Rome Statute) art 1.

13 ibid art 3. 
serious international crimes, ${ }^{14}$ and when possible, trying suspects. ${ }^{15}$ The Court seeks to end the culture of impunity by holding individuals accountable for their crimes and have a preventive and deterrent effect in order to reach international peace and stability around the world, and in particular, in post-conflict areas. ${ }^{16}$ The ICC's governing legal instrument, the RS, is a multilateral international treaty that grants it jurisdiction over four crimes: genocide, crimes against humanity, war crimes and the crime of aggression. ${ }^{17}$ The temporal and territorial jurisdiction of the ICC extends over crimes committed after July 2002 or the date on which a State ratified the $\mathrm{RS}^{18}$ on the territory of an SP or a third State that has accepted the ICC's jurisdiction. ${ }^{19}$ The personal jurisdiction of the ICC covers crimes committed by the nationals of an SP or a third State that accepted the ICC's jurisdiction. ${ }^{20}$

The ICC's jurisdiction can be triggered by three mechanisms: a referral by an $\mathrm{SP},{ }^{21}$ an investigation initiated by the Prosecutor ${ }^{22}$ or a referral by the United Nations (hereinafter ' $\mathrm{UN}^{\prime}$ ') Security Council. ${ }^{23}$ Indeed, even though the ICC is not a UN organization, it maintains close relations with this international body ${ }^{24}$ that has the power to grant it jurisdiction over a situation via a resolution adopted under Chapter VII of the UN Charter. However, it is important to point out that the ICC is a court of last resort that complements national courts and thus can only take over cases if States are unwilling or genuinely unable to do so. ${ }^{25}$ Additionally, it is imperative that the crime is of sufficient gravity ${ }^{26}$ and that its investigation serves the interests of justice. ${ }^{27}$ Moreover, as the ICC does not have its own police force or enforcement body, it relies on States' cooperation to give effect to the arrest warrants it issues by arresting and transferring the suspects, and by enforcing the sentences.

Once jurisdiction is established, investigation, prosecution and trial can eventually lead to ICR. ICR for crimes within the jurisdiction of the ICC is defined by article $25^{28}$ which reiterates that the Court has the legal capacity to exert its jurisdiction exclusively over natural persons as opposed to legal persons and States. ${ }^{29}$ It further outlines in a hierarchical manner different modes of participation that trigger ICR for the crimes listed in article 5 of the $\mathrm{RS},{ }^{30}$ namely commission, ordering, instigating and, aiding and abetting. ${ }^{31}$ ICR entails liability for punishment ${ }^{32}$ in the nature of imprisonment, sometimes accompanied by a fine and/or forfeiture of proceeds, property and assets. ${ }^{33}$ However, the path for ICR is long and complex: it comprises lengthy

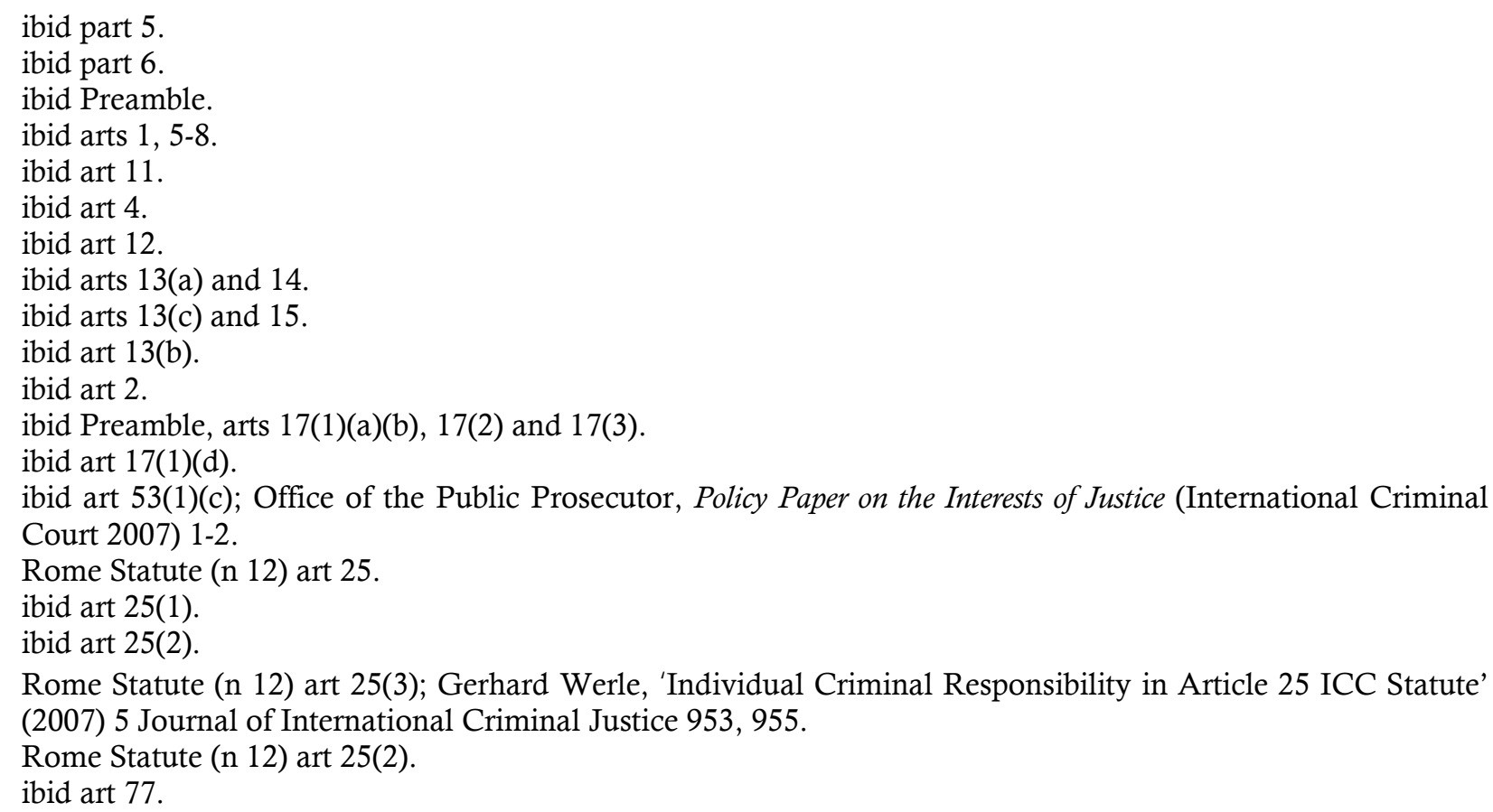


investigations and requires a strong evidentiary basis coupled with international cooperation. ${ }^{34}$ In this regard, evidence gathering is a crucial step in the prosecution of international crimes and is governed by the RS in conjunction with 'The Rules of Procedure and Evidence'. ${ }^{35}$ This legal framework establishes the standards for the collection, management, presentation, admission and evaluation of evidence. ${ }^{36}$ The Investigation Division of the Office of the Prosecutor is in charge of evidence gathering on the territory where crimes have allegedly been committed. ${ }^{37}$ The investigators have the duty to investigate both incriminating and exonerating situations equally in line with the truth-telling objective of the ICC. ${ }^{38}$ Again, the ICC expects the cooperation of $\mathrm{SPs}^{39}$ as they play a pivotal role in easing access to evidence, providing assistance and facilitating witness appearance. The gathered evidence can take various forms such as documents, objects, witness statements and testimonies, and is subject to an authoritative assessment by the judges who enjoy the discretion to evaluate their relevance and admissibility. ${ }^{40}$

Nevertheless, it is apparent that the foregoing procedural and substantive framework of the ICC is facing numerous challenges and reforms in the digital era. ${ }^{41}$ Indeed, the popularization of the Internet coupled with a widespread use of various communication technologies, in particular smartphones, have led to important developments in the prosecution process of international crimes. ${ }^{42}$ At the heart of these developments, one can identify a catalyst as powerful as it is interesting from a legal perspective: social media. The latter 'refers to websites and applications that are designed to allow people to share content quickly, efficiently, and in real-time' ${ }^{43}$ Accordingly, the main point of social media is digital content creation by its users, which varies from pictures and videos to texts and messages, shared publicly on platforms such as Facebook, Instagram and YouTube. ${ }^{44}$ User-generated content is, however, gaining importance over time and nowadays carries significant legal implications. ${ }^{45}$ In fact, social media brings a fruitful contribution to the body of ICL through the content it displays but also represents a dangerous weapon in the wrong hands. These two phenomena are two sides of the same coin and have largely contributed to the alteration of the legal landscape as will be shown and critically assessed in the following two sections.

34 ibid art 69, parts 5 and 9.

35 ibid arts 21, 51 and 69; International Criminal Court, The Rules of Procedure and Evidence (2nd edn, Enschede 2013) rules 63.

36 Rules of Procedure and Evidence (n 35) rules 63-75.

37 The Human Rights Center, 'Digital Fingerprints. Using Electronic Evidence to Advance Prosecutions at the International Criminal Court' (2014) UC Berkley School of Law 4.

38 Rome Statute (n 12) art 54(1)(a).

39 ibid art 86.

40 Alexa Koenig et al, 'Open Source Fact-Finding in Preliminary Examinations' in Morten Bergsmo and Carsten Stahn (eds), Quality Control in Preliminary Examination: Volume 2 (Torkel Opsahl Academic EPublisher 2018) 705; Mark Kersten, 'Challenges and Opportunities: Audio-Visual Evidence in International Criminal Proceedings' (Justice in Conflict, 4 March 2020) <https://justiceinconflict.org/2020/03/04/challenges-and-opportunitiesaudio-visual-evidence-in-international-criminal-proceedings/> accessed 1 July 2021.

41 Marta Poblet and Jonathan Kolieb, 'Responding to Human Rights Abuses in the Digital Era: New Tools, Old Challenges' (2018) 54(2) Stanford Journal of International Law 277-281.

42 Lindsay Freeman, 'Digital Evidence and War Crimes Prosecutions: The Impact of Digital Technologies on International Criminal Investigations and Trials' (2018) 41(2) Fordham International Law Journal 287-288.

43 Matthew Hudson, 'What is social media?' (The Balance Small Business, 8 May 2019) <www.thebalancesmb.com/what-is-social-media-2890301> accessed 1 July 2021.

44 Law Insider, 'Definition of social media' (Law Insider, 2020) <www.lawinsider.com/dictionary/social-media> accessed 22 April 2020.

45 Isabella Regan, 'Citizen digital evidence and international crimes' (Center for International Criminal Justice, 2020) <https://cicj.org/research/citizen-digital-evidence-and-international-crimes/> accessed 1 July 2021. 


\section{UGE Paving the Road to Individual Criminal Responsibility} A. A Panacea for the Inherent Procedural Weaknesses of the ICC

In this digital era, it is apparent that the proliferation of social media activity has particularly revolutionized the perspective on evidence so as to encompass UGE. Indeed, at the intersection of user-generated content and ICL, we find a plethora of UGE flooding social media and calling for the international community's attention. In this context, it is important to point out that the qualification as 'user' refers to an ordinary natural or legal person as opposed to traditional evidence providers such as investigation agents, experts or authorities. ${ }^{46}$ Consequently, the role of these users is becoming a pivotal addition in building an evidentiary basis for various crimes ${ }^{47}$ and bringing new challenges in courtrooms as will be discussed later in this article. Similarly, there is a growing reliance on open source evidence which represents any information retrieved from sources accessible to the general public. ${ }^{48}$ Accordingly, the focus will be on digital and technologically-derived open source evidence generated by social media users. ${ }^{49}$ The explosive increase of this category of evidence and its prevalence is ushering in a new era of online investigation and prompting a swift response from the ICC as to its use. ${ }^{50}$

It is arguable that the ICC is deploying efforts by broadening its horizons when it comes to evidence gathering. Its endeavour to integrate UGE is apparent from the '2016-2018 Strategic Plan of the Office of the Prosecutor'.' This plan reveals how helpful technology is in facilitating its monitoring role and alleviating the burden of proof. ${ }^{51}$ Moreover, it stresses the urgent need of the ICC to keep up with the latest technological developments. The suggested measures are staff training and hiring cyber-investigators and analysts in order to identify, collect and process UGE. ${ }^{52}$ These efforts stem from the procedural bars interfering with the proper functioning of the Court and the administration of justice faced by the ICC. Accordingly, the introduction of UGE brings about unique opportunities. This is due to the fact that UGE carries the potential of solving various procedural problems and enhances the ICC's effectiveness in fighting impunity. Indeed, the ICC has long been criticized for a lack of reactivity and relatively slowpaced procedures and investigations which jeopardize its efficiency in combating international crimes. ${ }^{53}$ This is mainly due to the complex nature of the atrocities investigated and the difficulty in collecting the required evidence. ${ }^{54}$ As a matter of fact, in most instances, investigations are compromised by the volatile political situation and lack of security in conflict areas ${ }^{55}$ Moreover,

46 Carlisle George and Jackie Scerri, 'Web 2.0 and User-Generated Content: legal challenges in the new frontier' (2007) 2 Journal of Information, Law and Technology 4.

47 Nikita Mehandru and Alexa Koenig, 'ICTS, Social Media, \& the Future of Human Rights' (2019) 17(1) Duke Law \& Technology Review 129, 129.

48 Nikita Mehandru and Alexa Koenig, 'Open Source Evidence and the International Criminal Court' 2019 Harvard Human Rights Journal <https://harvardhrj.com/2019/04/open-source-evidence-and-theinternational-criminal-court/> accessed 1 July 2021.

49 The International Bar Association, 'Evidence Matters in ICC Trials: An International Bar Association, International Criminal Court \& International Criminal Law programme report providing a comparative perspective on selected evidence matters of current importance in ICC trial practice' (2016) IBA ICL Perspectives 19.

50 Aida Ashouri et al, 'An overview of the use of digital evidence in international criminal courts' (2014) 11 Digital Evidence and Electronic Signature Law Review 115.

51 The Office of the Prosecutor, 'Strategic Plan 2016-2018' (2015) International Criminal Court, para 58.

52 ibid paras 59-62.

53 The International Bar Association (n 49).

54 Hans-Peter Kaul, 'The International Criminal Court - Current Challenges and Perspectives' (2011) Keynote for the Salzburg Law School on International Criminal Law 9.

55 Isabella Regan (n 45). 
UGE plays an imperative gap-filling role as it complements traditional evidence and is used to support the statements of witnesses. ${ }^{56}$ Accordingly, retrieving social media evidence creates a unique opportunity to boost the Court's efficiency. ${ }^{57}$ The ICC can only benefit from collective input ${ }^{58}$ to lower the evidentiary burden. ${ }^{59}$ It is furthermore essential to discuss the ICC's Achilles heel: it has neither an executive power nor an 'independent authority to compel the production of evidence'.$^{60}$ One of the major weaknesses of the ICC is its absolute dependency on the sincere cooperation of SPs. Investigators and prosecutors have their hands tied without prior permission by these States and can only count on their national mechanisms to proceed with evidence gathering.${ }^{61}$ It is thus indisputable that if UGE is judged to be sufficiently relevant and admissible, it may remedy the lack of evidence and resources, and therefore, it can bypass procedural issues. In addition, digital evidence available on social media, such as videos and images, can be an asset as they provide a perspective on the circumstances of an event and the location that can slip someone's mind ${ }^{62}$ This category of evidence can be more faithful than the testimonies of witnesses whose memory cannot always be accurate..$^{63}$ Moreover, the increasing reliance on digital evidence by criminal courts such as the ICC takes civil society's initiatives beyond naming and shaming, and gives effect to its efforts of public condemnation. The fact that exposure on social media has legal implications and opens the doors of the courtroom, slowly but surely, grants UGE the status of 'inevitable component'. ${ }^{\prime} 4$ This status implies that legal bodies have arrived at a point in which disregarding such digital evidence is controversial from the society's standpoint. Indeed, society might perceive the exclusion of this evidence as unfair and as misadministration of justice. Accordingly, its use is inescapable, and even necessary, in this digital context to cope with the new reality. ${ }^{65}$ It is nevertheless important to point out that even though UGE seems to be a solution to major procedural problems, it requires strict regulation due to the risks it brings.

\section{B. UGE: A Threat or a Blessing?}

As mentioned above, it is undeniable that UGE provides immense support for human rights advocacy and the condemnation of atrocities. However, it is equally apparent that UGE carry various limitations that undermine their power, value and influence. UGE, whether intentionally uploaded to denounce a crime or not, have a capacity of swift dissemination and add credence to existing evidence. ${ }^{66}$ Nonetheless, from a legal perspective, it inspires reluctance to a certain extent as even though it is an important source of evidence, it is not a miraculous remedy for the inherent procedural weaknesses of the ICC. In fact, the accuracy and authenticity of UGE is problematic as a video or an image can be taken from specific points of view and is

56 Alexa Koenig, "'Half the Truth is Often a Great Lie": Deep Fakes, Open Source Information and International Criminal Law (2019) 113 AJIL Unbound 250, 252.

57 The International Bar Association (n 49) 20.

58 ibid.

59 Lindsay Freeman (n 42).

60 Hans-Peter Kaul (n 54).

61 Alex Whiting, 'The ICC's New Libya Case: Extraterritorial Evidence for an Extraterritorial Court' (Just Security, 23 August 2017) <https://perma.cc/3963-2JGB> accessed 1 July 2021.

62 Mark Kersten (n 40).

63 The International Bar Association (n 50).

64 ibid.

65 Aida Ashouri et al (n 50).

66 Jelia Sane and Chiara Gabriele, 'Challenges and Opportunities: Audio-Visual Evidence in International Criminal Proceedings' (Justice in conflict, 4 March 2020) $<$ https://justiceinconflict.org/2020/03/04/challenges-and-opportunities-audio-visual-evidence-ininternational-criminal-proceedings/> accessed 1 July 2021. 
selective in what it shows. ${ }^{67}$ Additionally, graphic evidence may frequently and deliberately be staged by faking the occurrence of a certain event, photoshopped or wrongly attributed to an individual. One can also witness the rise of a phenomenon coined as the 'recycling of content' which consists of reusing old videos or images and putting a wrong date, time and location to generate rumours or aliment existing conflicts. ${ }^{68}$ Moreover, the context of such evidence is missing so suspects can offer an alternative explanation to exonerate themselves or justify their acts on the grounds of state of emergency or national security. Therefore, evidence can be manipulated for the purpose of conveying an erroneous message and can thus be biased and misleading. Furthermore, the creation of fake accounts, media falsification and defamation have the power to deprive UGE of any legitimacy. ${ }^{69}$ It is also important to keep in mind that, even though there is a widespread use of smartphones, these devices are still unevenly distributed, which makes UGE an inaccurate representation of reality. ${ }^{70}$ Issues of credibility are reinforced when the evidence is published or sent anonymously. In such cases, it is difficult to determine the provenance and reliability of such evidence. ${ }^{71}$

From a social perspective, this category of evidence represents a danger for both active generators of UGE and for passive consumers of UGE. ${ }^{72}$ Concerning the latter, an extensive exposition to evidence of horrendous crimes may engender a desensitization. In addition, too much information can have a counterproductive effect. Accordingly, repeated visualization of graphic content of heinous crimes banalizes atrocities and has a detrimental effect on society. ${ }^{73}$ When it comes to the former, the users of social media can face serious danger and in the worst cases their lives are threatened. Collecting and posting evidence is surely perilous and risky, especially, when the individual is not an expert or does not benefit from the protection of an authority. ${ }^{74}$ The more ordinary citizens engage with crime documentation on social media, the more they run the risk of retaliation and revenge orchestrated by persons they denounce. ${ }^{75}$ According to the foregoing, an extensive and far-reaching legal framework is necessary to regulate the identification, collection, processing and admissibility of UGE by well-established authorities and experts. It is moreover important to protect all the providers of information from retaliation and ensure a fair trial for the suspects whose cases are UGE-based.

The ICC, for instance, has enacted an e-court protocol ${ }^{76}$ where it specifies the measures it takes 'to ensure authenticity, accuracy, confidentiality and preservation of the record of

67 The International Bar Association (n 49) 24-3.

68 Nikita Mehandru and Alexa Koenig (n 48) 135.

69 Lindsay Freeman (n 42) 319.

70 Rebecca Hamilton, 'New Technologies in International Criminal Investigations' (2018) 112 Proceedings at the ASIL Annual Meeting 131, 131-133; Yvonne McDermott et al, 'Digital Accountability Symposium: Whose Stories Get Told, and by Whom? Representativeness in Open Source Human Rights Investigations' <http://opiniojuris.org/2019/12/19/digital-accountability-symposium-whose-stories-get-told-and-by-whomrepresentativeness-in-open-source-human-rights-investigations/> accessed 1 July 2021.

71 Mark Kersten (n 40).

72 Rebecca Hamilton, 'The Hidden Danger of User-Generated Evidence for International Criminal Justice' (Just Security, 23 January 2019) <www.justsecurity.org/62339/hidden-danger-user-generated-evidenceinternational-criminal-justice/> accessed 1 July 2021; The Human Rights Center (n 37) 4.

73 Jay Aronson, 'The Utility of User-Generated Content in Human Rights Investigations' in Molly Land and Jay Aronson (eds), New Technologies for Human Rights Law and Practice (CUP 2018) 129-148.

74 Rebecca Hamilton (n 70) 133.

75 Rebecca Hamilton (n 72); The Human Rights Center (n 37) 4; Rebecca Hamilton, 'User-Generated Evidence' (2018) 57(1) Colombia Journal of Transnational Law 1, 35-6.

76 International Criminal Court, Technical protocol for the provision of evidence, material witness and victims information in electronic form for their presentation during the Trial (International Criminal Court, 2008). 
proceedings' ${ }^{77}$ It furthermore sets formatting requirements, imaging and data standards and a specific numbering regime. Moreover, evidence retrieved from social media has to go through authentication and verification with the utmost precaution to ensure the legitimacy of the data. Accordingly, if meticulously regulated and vigorously taken into consideration, UGE alleviates the burden of proof. ${ }^{78}$ Therefore, to some extent UGE offers a way out from the impasses the ICC frequently faces. In addition, the right to a fair trial for the defendants is another important point at the heart of the administration of justice worth discussing. ${ }^{79}$ This right entails the duty of the ICC to ensure that the trial is 'fair and expeditious and is conducted with full respect for the rights of the accused and due regard for the protection of victims and witnesses' as outlined in article 64(2) of the RS. The protection of this right gets trickier in the digital era, especially in relation to equality of arms. This principle entails that a defendant must not be put in a disadvantageous situation vis-à-vis the prosecutor. As the focus in UGE gathering is more on incriminatory rather than exculpatory evidence, one would not have the full array of information. This phenomenon is directly linked to the very nature of social media as a denunciation and condemnation tool. Accordingly, in most instances, UGE exclusively serves the prosecution side and this creates a clear disparity between the two opponents. This is surely a problem encountered in proceedings not involving UGE, however, it is undeniable that this aspect is exacerbated by the character of digital evidence. Moreover, UGE produces an inherent cognitive bias for judges and prosecutors because graphic material can be very compelling and carries heavy consequences regarding their judgment. ${ }^{80}$ This surely intensifies the potential breach of equality of arms and invites legal bodies to double their efforts in protecting the right to a fair trial.

Accordingly, UGE can be considered as a blessing if, and only if, it is governed by a body of rules that combine strict regulation as to the collection and verification of UGE, the protection of producers and consumers of UGE and, the safeguard of the right to a fair trial for accused individuals. The international community ought to enact such a treaty or a protocol annexed to the RS to set a worldwide standard when it comes to UGE. This would maximize the benefits of UGE and monitor its use; otherwise, it might still be considered as a major threat.

\section{From Theory to Practice: ICC Arrest Warrant against Al-Werfalli}

Undoubtedly, it is necessary to see how the theory is put into practice. Indeed, an emblematic instance that illustrates the imperative role UGE can play in international crime prosecution is the issuance of an ICC arrest warrant against the Libyan national Al-Werfalli. After the fall of Muammar Gaddafi's regime, the situation in Libya escalated and swiftly shifted from hostilities between governmental forces and rebel groups during the 2011 uprising, to a non-international armed conflict among the rebel groups themselves. ${ }^{81}$ The Libyan National Army (hereinafter 'LNA'), a coalition of army units operating in Benghazi, is one of the predominant armed groups that largely contributed to a virulent spread of violence. It launched the 'Dignity Operation'

77 International Criminal Court, Regulation of the court (International Criminal Court, 2018) regulation 26.

78 Rebecca Hamilton (n 72) 27.

79 James Stewart, 'Fair Trial Rights under the Rome Statute from a Prosecution Perspective' (2014) ICTR Symposium.

80 Hamilton (n 72); Hamiltion (n 75) 133.

81 Geneva Academy, 'Non-international armed conflicts in Libya (Geneva Academy, 2020) <www.rulac.org/browse/conflicts/non-international-armed-conflicts-in-libya> accessed 1 July 2021. 
aimed at combating terrorist groups, mainly the Shura Council of Benghazi Revolutionaries, ${ }^{82}$ in which the elite forces unit 'Al-Saiqa Brigade' participated. ${ }^{83}$

The situation was referred to the ICC in 2011 by the UN Security Council acting under Chapter VII of the UN Charter ${ }^{84}$ in line with article 13(b) of the $\mathrm{RS}^{85}$ via Resolution $1970{ }^{86}$ The office of the prosecutor deems that this referral extends the ICC's jurisdiction beyond the 2011 Libyan civil war and covers all subsequent atrocities including the ongoing armed conflict. ${ }^{87}$ Due to the 'Al-Saiqa Brigade's' involvement in this conflict, the ICC issued two complementary arrest warrants, respectively on the $15^{\text {th }}$ of August $2017^{88}$ and the $4^{\text {th }}$ of July $2018,{ }^{89}$ for Al-Werfalli, an Axes Commander in the Brigade. He is accused of having personally murdered and ordered the execution of a total of forty-three persons in eight different incidents in the context of the 'Dignity Operation'.$^{90}$ Al-Werfalli thus faces charges of ICR pursuant to article $25(2)(a)$ and (b) of the $\mathrm{RS}^{91}$ for committing the war crime of murder as delineated in article $8(2)(\mathrm{c})(\mathrm{i})$ of the RS. ${ }^{92}$

At first sight, the arrest warrant follows the traditional ICC practice, however, its outstanding character stems from the fact that it is principally based on evidence retrieved from social media. ${ }^{93}$ The extra-judicial killings of LNA prisoners, either committed or ordered by AlWerfalli, have been recorded in eight videos and disseminated on Facebook and other social media platforms. ${ }^{94}$ The videos of the murders, their transcripts and several social posts by the Media Centre of the 'Al-Saiqa Brigade' itself formed the warrant's evidentiary basis. ${ }^{95}$ This arrest warrant is a milestone in the ICC's history and carries crucial legal implications for the international community. More precisely, it raises two remarkable aspects. Firstly, this unprecedented, but inevitable, move of the ICC is a significant step in its effort to accommodate conflicts in the digital age. ${ }^{96}$ Indeed, the ICC did not hesitate to break with its traditional evidentiary basis, investigation techniques and patterns to adapt to today's realities. ${ }^{97}$ By taking the plunge, the ICC clearly proves that it is abreast of technological developments and aware of their correlation with international crimes. Through this warrant, the ICC puts theory into practice and firmly acknowledges that the ever-growing interconnectivity urges the incorporation of open-source investigation. It thus demonstrates a general acceptance of UGE

82 Kevin Truitte, 'The Derna Mujahideen Shura Council: A Revolutionary Islamist Coalition in Libya (2018) 12(5) Perspectives on Terrorism 4, 4 and 5.

83 Camille Tawil, 'Operation Dignity: General Haftar's Latest Battle May Decide Libya's Future (2014) 12(11) Terrorism Monitor 8, 8-11.

84 United Nations Charter (adopted 26 June 1945, entered into force 24 October 1945) 1 UNTS XVI (UN Charter), ch VII.

85 Rome Statute, art 13(b).

86 UNSC Res 1970 (26 February 2011) UN Doc S/RES/1970.

87 ibid para 23.

88 Arrest Warrant 15 August 2017.

89 Arrest Warrant 4 July 2018.

90 Arrest Warrant 15 August 2017, paras 11-22; ibid para 17.

91 Rome Statute, art 25(2)(a)(b).

92 Rome Statute, art 8(2)(c)(i).

93 Rebecca Hamilton (n 72); The Human Rights Center (n 37) 4.

94 Arrest Warrant 15 August 2017.

95 ibid paras 11-21.

96 Emma Irving, 'And So It Begins... Social Media Evidence In An ICC Arrest Warrant' (Opinio Juris, 17 August 2017) <http://opiniojuris.org/2017/08/17/and-so-it-begins-social-media-evidence-in-an-icc-arrest-warrant/> accessed 1 July 2021; Alison Cole, 'Technology for Truth: The Next Generation of Evidence' (International Justice Monitor, 18 March 2015) <www.ijmonitor.org/2015/03/technology-for-truth-the-next-generation-ofevidence/> accessed 1 July 2021.

97 Emma Irving (n 96). 
and attaches to it considerable weight in legal practice. ${ }^{98}$ Secondly, and most importantly, by concretely embracing social media as a mine of evidence, the ICC sets a precedent and generates a strong incentive for future open-source investigations. ${ }^{99}$ Beyond an incentive, this emerging practice suggests a potential commitment to dive into the brutal crimes and gross human rights violations flooding the Internet. ${ }^{100}$ Consequently, pulling evidence from social media is a decisive stride towards enhancing the probative value of UGE and 'has tremendous promise for helping to build international criminal cases'. ${ }^{101}$ This arrest warrant offers a ray of hope for ongoing virulent conflicts around the world such as Syria ${ }^{102}$ and Yemen ${ }^{103}$ where UGE are overwhelmingly flowing and restores faith in legal bodies. Accordingly, as long as the ICC keeps up with these developments, one can assert that UGE plays a decisive role in paving the road to ICR. However, as rightly pointed out by Emma Irving, 'the warrant for Mr. Al-Werfalli is just the beginning of what will be a long, and likely complex, relationship between open source evidence and international criminal justice' ${ }^{104}$ This is due to the fact that with great opportunities come great risks, and therefore, the future of UGE will be shaped by a close interaction between technological development and the legal realm. The international community has the obligation to set a clear balance between the advantageous aspects of UGE in matters of facilitating prosecution and the regulation around UGE, the protection of stakeholders. Finding such an equilibrium is quite a challenging mission for the international community, but a necessary one in order to maximize the good administration of justice.

Overall, the international community is witnessing the rise of 'a new and fruitful body of potential evidence', ${ }^{105}$ namely UGE, that ought to be exploited, as done in the Arrest Warrant against Al-Werfalli, to tackle the widespread atrocities abundantly documented on social media. Accordingly, despite being beyond the ICC's reach, these atrocities finally and legitimately enter the courtroom. Nonetheless, even though UGE alleviates the pressure exerted on the ICC when it comes to evidence gathering and prosecution, some negative aspects related to reliability, security and fair trial arise. Such issues ought to be seriously examined and taken into account when establishing a comprehensive legal framework. Therefore, if correctly regulated and monitored UGE on social media is a practical addition to the legal body. However, social media, despite the advantages it offers for criminal prosecution, can produce significant harm as will be seen in the next section.

\section{An Ever Growing Role of Social Media in Fueling Mass Atrocities}

\section{A. Instrumental Use of Media for the Commission of International Crimes}

\footnotetext{
98 Christoph Koettl et al, 'Open Source Investigation for Human Rights Reporting in Digital Witness: A Brief History' in Sam Dubberley et al (eds), Digital Witness: Using Open Source Information for Human Rights Investigation, Documentation, and Accountability (OUP 2020) 27-28.

99 Emma Irving (n 96).

100 ibid.

101 Alexa Koenig (n 40).

102 Mark Kersten (n 40).

103 Dearbhla Minogue and Ruwadzano Makumbe, 'Digital Accountability Symposium: Harnessing UserGenerated Content in Accountability Efforts for International Law Violations in Yemen' (OpinioJuris, 18 December 2019) <http://opiniojuris.org/2019/12/18/digital-accountability-symposium-harnessing-usergenerated-content-in-accountability-efforts-for-international-law-violations-in-yemen/> accessed 29 July 2021.

104 Emma Irving (n 96).

105 Lindsay Freeman (n 42) 329.
} 
Starting from the Nazi weekly newspaper Der Sturmer ${ }^{106}$ to the Reichs-Rundfunk-Gesellschaft Nazi radio propaganda in 1923 prompting the Holocaust, ${ }^{107}$ a multitude of types of media took over the phenomenon of media weaponization. ${ }^{108}$ Indeed, a more recent striking example of a radio openly promoting hatred and contributing to the spread of hostility is the Radio Télévision Libre des Mille Collines (hereinafter 'RTLM'). The RTLM is a Rwandan government-sponsored radio channel also known as 'hate radio or 'the machete radio' that began broadcasting in August 1993 and opened the floodgates to the Rwandan Genocide. ${ }^{109}$ The RTLM was informally linked to militias and government officials and thus indirectly broadcasted the government's voice, a voice that progressively entered the Rwandan homes as popular entertainment for all social classes. However, the hidden, but primary, goal of this radio channel was to aliment the long-standing tensions between the Tutsis and their supporters, and the Hutus in Rwanda. ${ }^{110}$ The hate between these communities dates back to colonial historiography that portrayed them as two distinct races and ethnic groups. The Tutsis were depicted as having more in common with Europeans than Africans and thus hierarchically 'superior'. ${ }^{111}$ With time and political events, this separation became more rigid and intense, and eventually resulted in a deeprooted animosity. In this context, the RTLM broadcasts a deluge of disinformation and hate speech against the Tutsis to mobilize civil society and promote the government's anti-Tutsi agenda. ${ }^{112}$ The government's strategy to ensure the participation of the Rwandans in the extermination of the Tutsis consisted in generating a widespread feeling of fear of the Tutsis. The latter were portrayed as a serious danger and a threat to national security and unity. ${ }^{113}$ The demonization of the Tutsis coupled with an intense brainwashing translated into a wave of brutality and atrocities on the Rwandan territory. ${ }^{114}$ To further encourage the citizens to take part in this ethnic cleansing, the radio not only incited murder and issued directives on how to kill, but it also praised the murderers by qualifying them as the Rwandan heroes. ${ }^{115}$ Moreover, the radio station helped track individuals by providing information for the militia and security forces about the identity and location of the targets for extermination. ${ }^{116}$

These events ushered in a large-scale massacre resulting in a death toll ranging between 500,000 to 1 million persons in $1994 .{ }^{117}$ The perpetrators have since been brought to justice by

106 United States Holocaust Memorial Museum, 'Writing the News' (United States Holocaust Memorial Museum) <https://encyclopedia.ushmm.org/content/en/article/writing-the-news> accessed 29th July 2021.

107 Maja Adena et al, 'Radio and the Rise of the Nazis in Prewar Germany' (2013) <https://halshs.archivesouvertes.fr/halshs-00858992/document> accessed 1 July 2021.

108 Simon Adams, 'Hate Speech and Social Media: Preventing Atrocities and Protecting Human Rights Online (Global Centre for the Responsibility to Protect, 16 February 2020) <https://www.globalr2p.org/publications/hatespeech-and-social-media-preventing-atrocities-and-protecting-human-rights-online/> accessed 1 July 2021.

109 Hannah Richards et al, 'Studying "Radio Machete": Towards a Robust Research Programme' (2019) 21(4) Journal of Genocide Research 525, 525-527.

110 BBC News, 'Rwanda: How the genocide happened' (BBC News, 17 May 2011) <https://www.bbc.com/news/world-africa-13431486> accessed 1 July 2021.

111 ibid.

112 Jamie Metzl, 'Rwandan Genocide and the International Law of Radio Jamming' (1997) 91(4) The American Journal of International Law 628, 631-633.

113 Scott Straus, 'What Is the Relationship between Hate Radio and Violence? Rethinking Rwanda's "Radio Machete (2007) 35(4) Politics and Society 609, 612-613.

114 Jamie Metzl (n 112).

115 Jamie Metzl (n 112) 630.

116 Jamie Metzl (n 112) 631.

117 Linda Melvern, 'Missing the Story: the Media and the Rwanda Genocide' in Allan Thompson (ed), The Media and the Rwanda Genocide (Pluto Press 2007) 198. 
different judicial bodies, namely by conventional Rwandan courts, Gacacas, ${ }^{118}$ foreign national courts and the International Criminal Tribunal for Rwanda (hereinafter 'ICTR', 'the tribunal'). The ICTR was set by the UN Security Council in 1994 via Resolution $955 .{ }^{119}$ The mandate of this tribunal is to prosecute persons responsible for genocide and serious violations of international humanitarian law committed in the territory of Rwanda and neighbouring States, between 1 January 1994 and 31 December 1994. ${ }^{120}$ Even-though the ICTR has indicted 93 individuals and successfully sentenced 62 of them, the focus will be on the Prosecutor v Nahimana, Barayagwiza and Ngeze case, ${ }^{121}$ best known as the 'media case', a cornerstone in ICL's history. This was a landmark case as it was the first one that an international judicial body had held individuals criminally responsible for inciting civil society to commit international crimes via media. It thus highlights the pervasive and pernicious impact of media. Ferdinand Nahimara and Jean-Bosco Barayagwiza, respectively founder and high ranking member of the RTLM, have been judged for their behaviour during the Rwandan Genocide. The tribunal found that RTLM broadcasts qualified as a channel that conveyed hatred and an explicit call for the extermination of the Tutsi. ${ }^{122}$ The nature of the media and its obvious instrumental use led the tribunal to establish the causal link between what the radio diffused and the genocide on the grounds of ethnicity. ${ }^{123}$ Additionally, conclusive evidence of genocidal intent has been identified in the acts and sayings of both the masterminds behind RTLM and the speakers. ${ }^{124}$ According to the verdict of the ICTR, and in relation to the weaponization of the RTLM, both Barayagwiza and Nahimana, were found guilty of conspiracy to commit genocide, direct and public incitement to commit genocide, and genocide under article 2 (3)(a-c) of the Statute of the International Tribunal for Rwanda (hereinafter, "Statute"), ${ }^{125}$ and crimes against humanity, more precisely, extermination and persecution under article $3(\mathrm{~b})(\mathrm{h})$ of the Statute. ${ }^{126}$ However, after appeal, ${ }^{127}$ the Appeals Chamber decided that Nahimana was guilty of direct and public incitement to commit genocide and persecution as a crime against humanity. ${ }^{128}$ Barayagwiza was guilty of genocide under the mode of responsibility, extermination and persecution as a crime against humanity under the mode of responsibility of instigation and planning. ${ }^{129}$ Eventhough the two convicted individuals managed to mitigate their charges by appealing, this case is still a success in the history of ICL due to the implications it has for future similar cases.

Accordingly, the Rwandan Genocide is an instance of routinization of hatred through media. It illustrates the weaponization of a radio station widely and openly advocating for genocide as a national duty. However, it is crucial to emphasize that the case law the 'media case' prompted ${ }^{130}$ is a turning point in ICL as it changed the perception on the role of media and affirmed that its

118 Human Rights Watch, 'Justice Compromised The Legacy of Rwanda's Community-based Gacaca Court' (Human Rights Watch, 31 May 2011) <www.hrw.org/report/2011/05/31/justice-compromised/legacyrwandas-community-based-gacaca-courts> accessed 1 July 2021.

119 UNSC Res 955 (8 November 1994) UN Doc S/RES/955 (1994) para 1.

120 ibid para 1.

121 The Prosecutor $v$ Feidinand Nahamina, Jean-Bosco Barayagwiaz and Hassan Ngeze (Sentence and Judgement) ICTR99-51-T 3 December 2003.

122 ibid para 226.

123 ibid para 969.

124 ibid paras 957-969.

125 UN Security Council, Statute of the International Criminal Tribunal for Rwanda (as last amended on 13 October 2006) 8 November 1994, art 2(3)(a-c).

126 ibid 3(b)(h).

127 Feidinand Nahamina, Jean-Bosco Barayagwiaz and Hassan Ngeze $v$ The Prosecutor (Appeal) ICTR-99-52-A 28 November 2007.

128 ibid paras 1044-1052.

129 ibid paras 1053-1094.

130 The Prosecutor v Feidinand Nahamina, Jean-Bosco Barayagwiaz and Hassan Ngeze (n 121). 
misuse can trigger ICR. Accordingly, this case set an interesting precedent, succeeded in captivating the attention of the international community and encouraged proactive intervention. The lessons learned from the Rwandan Genocide are certainly key elements for understanding the evolution of this phenomena in a different context, namely the digital era.

\section{B. The Rohingya case: A Facebook-Fueled Ethnic Cleansing}

In the digital era, one can observe the same pattern of hate propaganda as during the Rwandan Genocide, however, through a different type of media: social media platforms. An emblematic illustration of the danger of social media and their role in fuelling atrocities is undeniably the Rohingya crisis.

Firstly, it is necessary to shed light on the political, economic and social background in Myanmar to gain a better understanding of why, and how, Facebook dominated the country and turned into a powerful weapon at an astonishing speed. The ubiquity of Facebook and its huge political impact are directly linked to a peculiar combination of factors. Politically, Myanmar has witnessed a sensitive and volatile situation marked by the transition from 26 years of military dictatorship to democracy and the rise to power of civilian governments since 2011 . $^{131}$ The subsequent drastic change in the political landscape prompted the liberalization of the telecommunication sector in 2013 which was otherwise tightly monitored under military rule. ${ }^{132}$ This liberalization had a domino effect. Indeed, it led to a chain of consequences that defined and shaped the current power and influence of Facebook in Myanmar. ${ }^{133}$ As soon as the telecommunication sector was liberalized, the prices of SIM cards swiftly came down, smartphones became affordable, and 4G networks became easily and speedily accessible. ${ }^{134}$ Moreover, most smartphones were preloaded with the Facebook app and mobile phone operators set special offers enabling the use of Facebook without data charges. ${ }^{135}$ This initiative has also been taken by Mark Zuckerberg, the CEO of Facebook, who launched 'Internet.org' aiming to provide developing countries with the Internet. As part of this 'humanitarian' project, the app 'Free Basics' has been developed to subsidize the use of Facebook on smartphones. As Myanmar is an economically weak country with a particularly poor population, especially in rural areas, such offers could only be attractive and promote the popularization of Facebook. ${ }^{136}$ Socially, Myanmar's population had been totally disconnected, marginalized from the online world and isolated under the dome of the military junta until 2011. ${ }^{137}$ Additionally, there are inherent religious and ethnic tensions between the Rakhine Buddhists and the Rohingya Muslims in Myanmar. ${ }^{138}$ Accordingly, the deadly combination of an authoritative government in disguise, an unprecedented booming market of mobile connectivity and ethno-religious

131 Ronan Lee, 'Extreme Speech in Myanmar: The Role of State Media in the Rohingya Forced Migration Crisis' (2019) 13 International Journal of Communication 3203, 3208.

132 ibid 3207.

133 ibid 3208-3211.

134 Lisa Brooten, 'When Media Fuel the Crisis: Fighting Hate Speech and Communal Violence in Myanmar' in Jamie Matthews and Einar Thorsen (eds), Media, Journalism and Disaster Communities (Springer 2020) 217-9.

135 Christina Fink, 'Dangerous Speech, Anti-Muslim violence, and Facebook in Myanmar' (2018) 71 Journal of International Affairs 43, 44.

136 The World Bank, 'Poverty Report- Myanmar Living Conditions Survey 2017' (The World Bank, 26 June 2019) <www.worldbank.org/en/country/myanmar/publication/poverty-report-myanmar-living-conditions-survey2017> accessed 1 July 2021.

137 Lisa Brooten et al, "Traumatized victims and mutilated bodies: Human rights and the "politics of immediation" in the Rohingya crisis of Burma/Myanmar' (2015) 77(8) The International Communication Gazette $718,718$.

138 BBC News, 'Why is there communal violence in Myanmar?' (BBC News, 3 July 2014) <https://www.bbc.com/news/world-asia-18395788> accessed 1 July 2021. 
tensions turned Facebook into an instrument of hate propaganda. It is predictable that the swift rise of transnational media giants such as Facebook coupled with an abrupt rollback of censorship is dangerous. This is especially the case due to the sudden access to an enormous flow of information, and misinformation. Even more alarming is Myanmar's perception of the platform: Facebook is the Internet. It is considered as the exclusive authoritative source of news and information. The information displayed on Facebook is never critically processed, evaluated or questioned by its recipients which reinforces the non-existent distinction between the social media platform and the Internet as a whole. ${ }^{139}$

This situation played in favour of Myanmar military personnel ${ }^{140}$ and ultranationalist Buddhists. ${ }^{141}$ They promoted an online campaign of hate and incitement for rape and murder targeting the Muslim community. ${ }^{142}$ The exact same pattern that was employed during the Rwandan Genocide by the government can also be observed in the Rohingya crisis even though via a different instrument. The military gave an erroneous image of the Muslim community and presented it as a threat to national unity and culture. They argued that the community is planning on taking over the country through economic domination and increased birth rates to expand the community. ${ }^{143}$ Disinformation campaigns started unfolding and exacerbated the wave of Facebook-enhanced atrocities. ${ }^{144}$ An example of how disinformation can cause brutality offline is certainly the horrendous incident in 2014. A Buddhist monk posted on his Facebook account that a Muslim shop owner raped a Buddhist employee which was interpreted as a call to fight by the Buddhist community. ${ }^{145}$ Obviously, a conflict erupted that resulted into two deaths, a Muslim and a Buddhist. At the end, it turned out that the rape allegation was false. ${ }^{146}$ This is just one of many examples of incidents that have sparked in Myanmar and resulted in over 24.000 deaths and a huge refugee crisis in neighbouring countries. ${ }^{147}$ Villages were razed to the ground, women and girls were raped and killed. Many Rohingyas were tortured to death or burned alive in their houses. ${ }^{148}$ The Rohingya crisis therefore emphasizes the extent to which what happens on social media is manifested in real life and how far-reaching the consequences can be.

Overall, media plays a pivotal role in fuelling atrocities through the course of history, beginning with newspapers in the Nazi era and radio during the Rwandan Genocide, and ending with

139 Libby Hogan and Michael Safi, 'Revealed: Facebook hate speech exploded in Myanmar during Rohingya crisis' (The Guardian, 3 April 2018) <https://www.theguardian.com/world/2018/apr/03/revealed-facebook-hatespeech-exploded-in-myanmar-during-rohingya-crisis > accessed 1 July 2021.

140 Paul Mozur, 'A Genocide Incited on Facebook, With Posts From Myanmar's Military' (The New York Times, 15 October 2018) <https://www.nytimes.com/2018/10/15/technology/myanmar-facebook-genocide.html> accessed 1 July 2021.

141 Christina Fink (n 135) 44.

142 Steve Stecklow, 'Why is Facebook losing the war on hate speech in Myanmar' (Reuters Investigates, 15 August 2018)<https://www.reuters.com/investigates/special-report/myanmar-facebook-hate/> accessed 1 July 2021.

143 Gabriele Cosentino, Social Media and the Post-Truth World Order The Global Dynamics of Disinformation (Palgrave Mcmillan 2020) 199.

144 Lisa Brooten et al (n 137) 718.

145 Gabriele Cosentino (n 143) 120.

146 Christina Fink (n 135) 46.

147 UNHCR, 'United Nations seeks US\$920 million for Rohingya humanitarian crisis in 2019 (UNHCR, 15 February 2019) <www.unhcr.org/en-us/news/press/2019/2/5c667ecf4/united-nations-seeks-us920-millionrohingya-humanitarian-crisis-2019.html> accessed 1 July 2021.

148 Republic of The Gambia v Republic of the Union of Myanmar (Application instituting proceedings and Request for the indication of provisional measures) [2019] ICJ <https://jusmundi.com/en/document/pdf/other/enproceedings-instituted-by-the-republic-of-the-gambia-against-the-republic-of-the-union-of-myanmar-on-11november-2019-application-instituting-proceedings-and-request-for-the-indication-of-provisional-measuresmonday-11th-november-2019> accessed 1 July 2021, paras 9-15; Sigal Samuel, 'Facebook is reckoning with its role in a textbook example of ethnic cleansing'(Vox, 7 February 2019) <https://www.vox.com/futureperfect/2019/2/7/18214351/facebook-myanmar-rohingya-muslims> accessed 1 July 2021. 
Facebook in the Rohingya crisis. The common denominator is certainly the instrumentalization and weaponization of media. It is a strategy to mobilize civil society via online hate speech and incite the commission of international crimes. Due to the serious and critical character of such phenomena, one can only reflect upon the international response and scrutinize it. The questions of whether these tragic events triggered a reaction and which legal implications it entails may also arise. The following section will be devoted to answering these two crucial questions and eventually offer an insight in a possible future.

\section{The Response of the International Community: Too Little Too Late?}

The Rohingya crisis captured the attention of the international community ${ }^{149}$ and, in particular, the UN. It asserted in its '2018 Report of the Independent International Fact-Finding Mission on Myanmar' that Facebook played a pivotal role in the spread of hate resulting in real-world atrocity. ${ }^{150}$ The High Commissioner for Human Rights qualified the crisis as 'a textbook example of ethnic cleansing'. ${ }^{151}$ Moreover, the Gambia filed a case against Myanmar at the International Court of Justice (hereinafter ' $\mathrm{ICJ}$ ') under the Convention on the Prevention and Punishment of the Crime of Genocide (hereinafter 'the Convention') in relation to the Rohingya minority. ${ }^{152}$ The Gambia claimed that Myanmar violated its obligations under the Convention and in particular, but not restricted to, articles I, III, IV, V and VI. ${ }^{153}$ The Gambia collected voluminous evidence and asked the ICJ to declare that Myanmar has indeed breached multiple obligations under the Convention. It also requested the ICJ to order Myanmar to cease its wrongful acts, punish the perpetrators before a competent tribunal, make reparations to the victims and offer a guarantee of non-repetition. ${ }^{154}$ The Gambia further requested provisional measures $^{155}$ to avoid further harm, in line with Article 41 of the RS, ${ }^{156}$ and Articles 73, 74 and 75 of the Rules of Court. ${ }^{157}$ The response of the international community was tardive as the crisis officially started in May 2015 and only got worthwhile attention in November 2019. However, it seems to bear fruit as the request of the Gambia for provisional measures was successful. The ICJ issued an order on January 2020 ordering the State of Myanmar to take all measures in order to protect the Rohingya vulnerable group, cease all violence and killings and, comply with its obligations under the Convention ${ }^{158}$ in a time frame not exceeding four months from the issuance of the order. ${ }^{159}$

\footnotetext{
149 Yanghee Lee, 'Statement by Ms. Yanghee Lee, Special Rapporteur on the situation of human rights in Myanmar at the 37th session of the Human Rights Council' (United Nations Human Rights Office of the High Commissioner, $12 \quad$ March 2018) <https://www.ohchr.org/EN/NewsEvents/Pages/DisplayNews.aspx?NewsID=22806\&LangID=E > accessed 1 July 2021.

150 Human Rights Council, 'Report of the independent international fact-finding mission on Myanmar' (10-28 September 2018) A/HRC/39/64, para 74.

151 UN, 'UN human rights chief points to "textbook example of ethnic cleansing" in Myanmar' (UN News, 11 September 2017) <https://news.un.org/en/story/2017/09/564622-un-human-rights-chief-points-textbookexample-ethnic-cleansing-myanmar> accessed 1 July 2021.

152 Application of the Convention on the Prevention and Punishment of the Crime of Genocide (The Gambia v Myanmar) (order) [2020] General List No 178.

153 The Gambia v Myanmar, para 111.

154 The Gambia v Myanmar, para 112.

155 The Gambia v Myanmar, para 113.

156 Rome Statute (n 12) art 41.

157 International Criminal Court (n 77) regulations 73-75.

158 The Gambia v Myanmar, para 120.

159 The Gambia v Myanmar, para 5.
} 
In general, strict action and, especially regulation, are urgently required when it comes to the use of social media as a tool for the commission of international crimes. Apart from the significant, but not so swift, reaction of the Gambia, what we have seen for now is too little too late, especially from Facebook's side. ${ }^{160}$ Indeed, it is only in August 2018 that Facebook started taking action by removing the main Facebook and Instagram accounts responsible for the hate propaganda even though the horrific events erupted in 2015. If Facebook would have been more reactive to some activists and journalists desperate call for help, it could probably have averted a lot of harm. Its slow reaction is an emblematic and dramatic instance of a wave of hate speech not properly accounted for. One must nevertheless admit its efforts to put an end to its misuse. Indeed, a human rights Impact Assessment with the title 'Facebook in Myanmar' by Business for Social Responsibility has been carried out. ${ }^{161}$ It is an advisory non-profit organization that carries out human rights checks in line with the UN Guiding Principles on Business and human rights. ${ }^{162}$ Even though at the beginning of the report, the blame is put exclusively on the sociopolitical situation in Myanmar to mitigate the link with the atrocities, it ends with an acknowledgement that the platform did play a critical role. ${ }^{163}$ Moreover, it finally states that there is a pressing need for hiring local staff. This is crucial as locals have an insightful knowledge of the situation in Myanmar and can ensure an effective and detail-oriented monitoring of Facebook posts. ${ }^{164}$ Additionally, Facebook employees are working on removing all the posts that go against the Community standards of Facebook, identifying and eliminating fake accounts and inflammatory posts. It is undeniable that, due to external pressure, Facebook is trying to comply with its responsibilities seriously and implement solutions. However, the situation should be taken on a more serious level. Indeed, comprehensive regulation is indispensable and pressing. In this regard, 'The New Forensics: Using Open Source Information to Investigate Grave Crimes report, also known as the 'Bellagio report', is an important report. It is based on the first workshop diving into 'the probative power and potential of open source investigations for legal accountability'. ${ }^{165}$ This report ought to be interpreted as a recommendation and a leading inspiration for the international community. It should be implemented in the form of a treaty, an annexed protocol to the RS or an RS amendment and then swiftly operationalized.

One of its guiding principles is consistency on all levels: terminology, definitions, standards and guidelines. ${ }^{166}$ Such a unified legal framework would definitively, and in an organized manner, incorporate social media dimensions to serve the proper administration of justice at the international level. Moreover, this thematic begs the question of which options of ICR would be available in instances where a certain social media platform has its part of responsibility in fuelling atrocities. One could argue that the executives of social media companies can be responsible for facilitating or aiding and abetting for the commission of a crime under article 25(3)(c) of the RS. Others may advocate that they are guilty of omission as they did not exert

160 Julia Wong, 'Overreacting to failure: Facebook's new Myanmar strategy baffles local activists' (The Guardian, 7 February 2019) <https://www.theguardian.com/technology/2019/feb/07/facebook-myanmar-genocideviolence-hate-speech> accessed 1 July 2021.

161 Alexa Warovka, 'An Independent Assessment of the Human Rights Impact of Facebook in Myanmar' (Facebook, 5 November 2018) <https://about.fb.com/news/2018/11/myanmar-hria/> accessed 1 July 2021.

162 UNHCR Protect, respect and remedy: a framework for business and human rights: report of the Special Representative of the Secretary-General on the Issue of Human Rights and Transnational Corporations and Other Business Enterprises (7 April 2008) A/HRC/8/5.

163 Business for Social Responsibility, Human Rights Impact Assessment: Facebook in Myanmar (2018) 23-24, 30; Alexandra Stevenson, 'Facebook Admits It Was Used to Incite Violence in Myanmar' (The New York Times, 6 November 2018) <https://www.nytimes.com/2018/11/06/technology/myanmar-facebook.html> accessed 1 July 2021.

164 Business for Social Responsibility (n 163) 26.

165 The Human Rights Center (n 37) 13.

166 ibid 15-17, 19; Nikita Mehandru and Alexa Koenig (n 47) 139. 
any monitoring or filtering on the content displayed on their platforms. However, the mens rea to do so is obviously complex to establish due to the difficulty of proving in practice the correlation between the crime and the social media platform. It is nevertheless a hot topic that ought to be looked into by the international community.

When it comes to recommendations, due to the weaponization of social media, the international community should consider establishing a special chamber in the ICC to tackle all conflicts inflamed by social media. This chamber would mainly deal with ICR triggered by social media content and so develop expertise in handling cases primarily based on digital evidence. Additionally, it is a considerable step in adapting the concept of ICR to the reality of many atrocities in the digital era. It offers the possibility to punish not only individuals on the basis of their heinous activities, but also the high-ranked individuals behind social media companies for their passivity vis-à-vis the misuse of their platforms. Of course, a legal basis is necessary for such reforms and it may take various forms: a multilateral treaty, a special protocol annexed to the RS or an amendment of the RS. Any of these measures would preferably build on the 'Bellagio Report' and provide a guideline for prosecution. It needs to include the challenges and issues raised by social media and ensure fairness, impartiality and legitimacy. Over time, and with the development of a comprehensive body of case law, the international community will count more experts in issues at the intersection of technological development and the administration of criminal justice. This can only serve to accommodate the digital era and fill in the legal lacuna. Most importantly, there is general consensus that the body of ICL ought to evolve in the sense of enhancing ICR for the purpose of ending impunity and promoting a culture of responsibility. Overall, to date, social media is half-way between a threat and a blessing and requires strict regulation to turn into a valuable asset in the realm of ICL.

\section{Conclusion}

This article highlighted the astonishingly growing impact of social media on the legal sphere and in particular the domain of ICL. Indeed, it has an effect on various stages of criminal proceedings, namely evidence gathering, investigation and prosecution that can eventually lead to ICR. The prominence of UGE on social media has led to both positive and negative implications on the ICL sphere. Clearly, this type of evidence is a double-edged sword. On the one hand, it had a significant impact on evidence gathering as it opened the door for a flow of new evidence. As highlighted by the example of the Arrest Warrant issued by the ICC against A1-Werfelli on a digital evidentiary basis, UGE is being exploited in practice and is bearing fruits. Nevertheless, these developments also bring along unique legal challenges. Such challenges are linked to issues of reliability, accuracy, credibility, authenticity, bias ${ }^{167}$ and fair trial. Moreover, it has considerable downsides when it comes to the security of individuals and the protection of their rights. As a matter of fact, this type of evidence turns out to be life-threatening for its producers and harmful for society at large due to the compelling graphic content. Accordingly, it can only be counted as a blessing if it is strictly regulated, ensures the protection of both producers and consumers of UGE, and respects the right to a fair trial of a defendant whose case is based on UGE. On the other hand, the phenomenon of weaponization of social media does not go unnoticed. In the past, media has already been instrumental in and misused for fuelling international crimes, in particular during the Rwandan Genocide. The amplification of this phenomena in today's context is no surprise due to the swift development of online platforms and their widespread use as illustrated by the Rohingya crisis. No matter which type of media is utilized, radio or social media, a distinct pattern is followed by legal or natural persons to spread hate, materializing in horrendous offline brutality. One can therefore hope that the latter case will trigger ICR by taking the example of the conviction of two individuals responsible for hate

167 Mark Kersten (n 40). 
propaganda in the 'media case'. However, in order to obtain such a result, it is imperative that the existing legal framework is strengthened and updated in order to encompass evidence collection, examination, processing and preservation in the digital era. In this sense, the establishment of a special chamber within the ICC with a specific and exhaustive protocol might be a stepping stone for the evolution of the legal framework and fulfilment of the existing legal lacuna. This Chamber would find the legal basis for its powers in a binding legal document regulating all the discussed aspects of social media in relation with ICL. Regulation is key in order to contain the disadvantageous sides of most recent developments, and avoid horror, and enhance the more advantageous one with a vision to promote justice and transform UGE in the much needed mine of evidence. 